\title{
The influence of soil-foundation-structure interaction on the overall behaviour and diseases of a medieval building in Pisa
}

\author{
S. Caprili ${ }^{1}$, F. Mangini ${ }^{1}$, W. Salvatore ${ }^{1}$, G. Scarpelli ${ }^{2}$ \\ $\&$ N. Squeglia ${ }^{3}$ \\ ${ }^{1}$ Department of Civil and Industrial Engineering, \\ University of Pisa, Italy \\ ${ }^{2}$ Department of Science and Engineering of Matter and the Environment, \\ Polytechnical University of Marche, Italy \\ ${ }^{3}$ Department of Energy, Systems, Territory and \\ Construction Engineering, University of Pisa, Italy
}

\begin{abstract}
The University of Pisa was established in 1343 , but it was only in the $16^{\text {th }}$ century that a specific venue, Palazzo La Sapienza, was built. The building was subjected to various modifications in relation to the users' requirements, with the following irregular structural growth due the absence of a specific and organized global and general scheme. The present paper describes the investigations carried out on the construction and on the foundation soil to clarify their mutual interactions and explain some of the damage today affecting the building. A deep in situ experimental test campaign was executed to define masonry typology, dimensions of structural elements, mechanical properties of materials, geotechnical parameters of the soil and foundations' geometry and masonry characteristics. Dynamic properties of the subsoil were investigated in order to properly define the local seismic action and the local influence of subsoil profile, necessary for the execution of safety assessments on the global model of the building.

Keywords: soil-structure-foundation interaction, cultural heritage, masonry buildings, local seismic response analysis, vulnerability assessment.
\end{abstract}




\section{Introduction}

Historical masonry buildings in Italy were usually realized by not following modern seismic design principles and only on the basis of rule of thumb and experience. Recent and past seismic events (Friuli 1976, Umbria-Marche 1997, L'Aquila 2009 and Emilia-Romagna 2012) evidenced the high vulnerability of the Italian cultural heritage and the factors mainly affecting its structural response. Two main categories of problems can be recognized: the first ones are related to the morphological and structural configuration of the buildings, the second ones, on the other hand, are related to site effects and to the interaction among soil, foundation and superstructure. Despite the wide technical effort to codify a procedure for the assessment of historical masonry buildings [1-3], the influence of soil-structure interaction (SSI) and of site effects on the global static and dynamic response of existing buildings remains not sufficiently investigated topic, frequently not applied to real structures/structural aggregates.

The necessity of a detailed knowledge of the SSI is a widely discussed topic in the current scientific literature, for what concerns both the static and the seismic behaviour of the structure. Masia et al. [4] elaborated a soil-structure interaction model for the simulation of the structural response of masonry buildings subjected to soil movements. This model, used to reproduce the cracks in masonry wall panels, allowed one to understand the influence of soil and of corresponding relative subsidence on the development of cracks and damages on the superstructure, often due to the modification and the increase of loadings on the construction.

The importance of site effects on the dynamic behaviour of structures was highlighted by the observation of structural damages caused by recent seismic events: during the Emilia-Romagna earthquake (2012) the local amplification of seismic action due to soft soil led to liquefaction phenomena, with detrimental effects on the overall structure [5]. According to [1], two approaches are allowable to include site effects in the evaluation of the real seismic demand on buildings, i.e. the adoption of an amplification factor (S) based on soil category and on the stratigraphic distribution or, otherwise, the execution of local seismic response investigations. Many studies in the current scientific literature evidenced the relevance of SSI problems for the behaviour of buildings and bridges. Two different approaches are generally proposed for the analysis of the dynamic response of Soil-Foundation-Structure (SFS) systems [6]; the first "direct method" usually adopts a global finite element model including soil, foundation, structure and their non linearities, allowing the reaching of detailed results towards a high computational effort. The "substructure method", on the other hand, separately analyzes the soil-foundation system and the response of the superstructure $[7,8]$, representing the soil-foundation interaction with spring elements of specific stiffness.

Despite the large investigations about the correct way to represent the SSI, in the current engineering practice structural systems are often considered fixed at foundation, whose behaviour is separately analyzed [9]. This assumption is usually justified assessing that the flexibility of the soil-foundation system 
generally moves the fundamental vibration periods towards lower values of the spectral acceleration, with lower resulting seismic demand. Recent studies [10] evidenced, on the other hand, the impossibility to determine, without the investigation of the SSI, whether it increases, or decreases, the seismic demand for the considered structure.

The structural analysis of the static and seismic vulnerability of existing buildings, especially in the case of cultural heritage, cannot therefore neglect geotechnical aspects. This would typically require an appropriate site investigation to determine the soil stratigraphy, local amplification factors and an assessment of type and consistency of foundations to define the geotechnical model for the analysis of the SSI. In the present paper, the approach followed for the analysis of SSI and for the subsequent modelling of the soil-foundationstructure (SFS) system is applied for the assessment of the static and seismic vulnerability of Palazzo La Sapienza in Pisa (Italy).

\section{La Sapienza Palace: origin, transformations and state of the art}

Palazzo La Sapienza in Pisa, whose construction started at the beginning of the $13^{\text {th }}$ century, is characterized by a trapezoidal plan with a central open court, with global gross dimensions equal to $80.0 \mathrm{~m}$ per $53.7 \mathrm{~m}$ and three storeys with interstorey height variable between $430 \mathrm{~cm}$ and $550 \mathrm{~cm}$. The actual configuration of the palace is the outcome of several modifications executed during the centuries to satisfy the requirements imposed by the activities developed inside.

A detailed investigation about the historical changes was executed, allowing the whole knowledge of the actual "aggregate" and of its single structural units. The building, originated from the medieval structures of Piazza del Grano and of Dogana del Sale adsorbing the adjacent single masonry units and tower houses, was progressively extended to house the seat of the University of Pisa.

At the beginning of the $20^{\text {th }}$ century, the necessity to increase the available place for the books owned by the University Library leaded to the enlargement of the building, with the demolition of many internal bearing walls, the super elevation of the west part of about $3.0 \mathrm{~m}$, the modification of shape and dimensions of doors and windows, the realization of new storey slabs and others.

The enlargement of the building, with the following increase of vertical loads, continued during 1900, transforming the original Renaissance structure of the Palace, made up of a relative small volume of two storeys into the actual massive three storey building (Figure 1). In general, the progressive deterioration of the
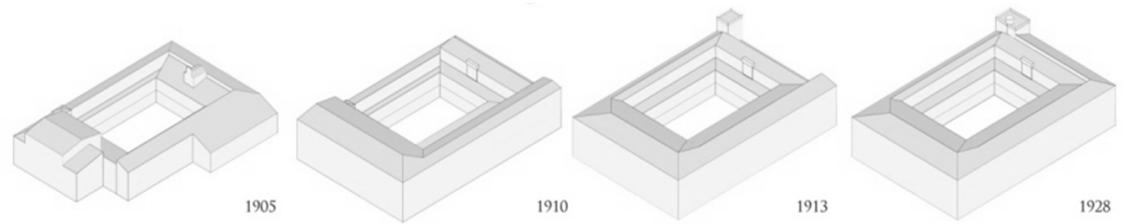

Figure 1: Structural modifications during the first two decades of 20th century. 
building, evidenced by a diffused cracking scenario, was the direct consequence of structural interventions that neglected the original configuration of the Palace and its incapability to sustain higher loads respect to the design ones.

Nowadays, the ground floor of the building houses lecture halls of the University of Pisa, the historical Aula Magna, technical rooms and other services; the first and the second floors are used by departments and by the University Library.

Several in situ survey campaigns were executed to investigate the mechanical characteristics of structural elements (i.e. masonry walls, vaults, horizontal storeys, roof system, foundation) and of materials, necessary for the assessment of structural safety. The bearing structure of the building is made up of masonry walls of thickness variable between 100 and $120 \mathrm{~cm}$ (external walls) and 45 and $50 \mathrm{~cm}$ (internal walls). The floor systems are mainly of two main categories: vaulted masonry at ground floor with different geometry and thickness and horizontal floors with steel profiles and masonry light blocks. The roof is made up of steel and wooden trusses with different geometrical configuration of the bearing elements; in correspondence of the new Aula Magna the vault is directly supported by seven masonry truss beams.

\section{Geotechnical investigations, seismic input, foundations survey}

\subsection{Soil investigations}

An experimental test campaign including continuous core drilling, static penetration tests (CPTU), seismic dilatometer tests (SDMT) and dynamic penetration test (DPSH), was executed (Figure 2). Each of the two internal drilling (S1 and S2) was instrumented with a Casagrande piezometer. The results of both laboratory and in situ testing allowed the determination of physical and mechanical properties of the soils and the selection of geotechnical parameters to characterize the shear strength and the stiffness of the foundation soils.

Two main horizontal beddings were determined (Figure 3(a)). The first horizontal bedding, called " $A$ - Complex", of thickness equal to about $14.0 \mathrm{~m}(-9.0 \div+5.0 \mathrm{~m}$ a.s.l. $)$ that includes an artificial earthfill followed by sands, silts and clays in layers of varying thickness, different colours and poor lateral continuity (A1); in the lower part of the complex a layer of fine sands interbedded with thin silty layers is present (A2). The second horizontal bedding, called "B-Complex" $(-9.0 \div-35.0 \mathrm{~m}$ a.s.l.), is made up of four different layers: upper clays (B1, up to $-19.0 \mathrm{~m}$ a.s.l.) slightly overconsolidated, having medium to high plasticity and low consistency; intermediate clays (B2, between -19.0 and $-23.0 \mathrm{~m}$ ) with clays and silts in varying percentages and higher degree of overconsolidation and consistency with respect to B1; intermediate sands (B3, between -23 and $-25 \mathrm{~m}$ a.s.l), with fine silty sands of dark gray colour, and, finally, silty clays of dark grey colour (B4, between -25 and $-35.0 \mathrm{~m}$ a.s.1.) normally consolidated or slightly overconsolidated and of medium consistency. 
Laboratory tests allowed the estimation of the physical properties of the different soils, and the construction of profiles of the unit weight $\gamma$, of the natural water content $\mathrm{W}_{\mathrm{N}}$, of the void index $\mathrm{e}_{0}$, of the liquid limit $\mathrm{W}_{\mathrm{L}}$, of the index of plasticity IP and of the clay content CF, all with respect to depth. Moreover, the profiles of compression index $\mathrm{C}_{\mathrm{c}}$, of the swelling index $\mathrm{C}_{\mathrm{s}}$, of the coefficient of primary and secondary consolidation, respectively $\mathrm{C}_{\mathrm{v}}$ and $\mathrm{C}_{\alpha}$, of the permeability $\mathrm{k}$ and of the overconsolidation ratio OCR, with depth were also determined.

The shear strength of the fine graded soils was investigated through the execution of triaxial tests in undrained conditions (TX CIU) on undisturbed samples. The tests were focused only on those layers of the foundation soil in which the sampling was possible (i.e. layers A1, B1and B2). SMDT tests allowed the determination of the of the shear waves velocity $V_{s}$; layers A1, A2 and $\mathrm{B} 1$ are characterized by values of $V_{s}$ almost constant and equal to about $200 \mathrm{~m} / \mathrm{s}$, layer B2 shows values up to $400 \mathrm{~m} / \mathrm{s}$, layer B3 presents a $V_{s}$ equal to $500 \mathrm{~m} / \mathrm{s}$, falling to the lower values of $200-300 \mathrm{~m} / \mathrm{s}$ for layer B4.

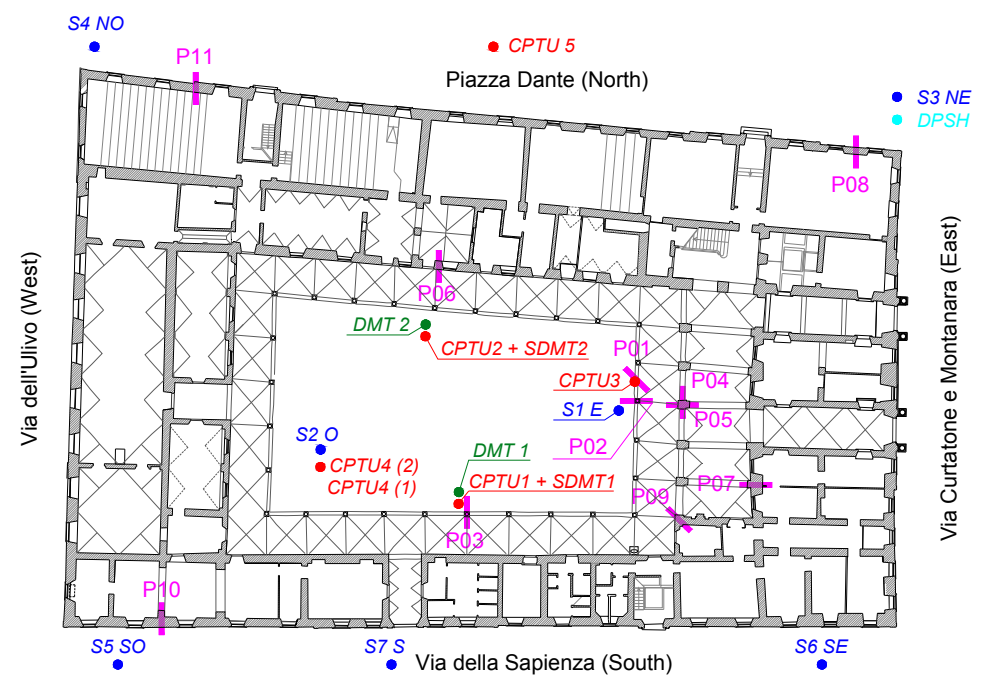

Figure 2: Location of the boreholes and of the in situ tests.

The experimental results for samples of layers A1, B1, B2 and B4 (from resonant column tests) allowed the determination of shear modulus $G$ (normalized to its maximum value $\mathrm{G}_{0}$ ) and of damping $D$. The experimental data were then used to define the parameters necessary to relate stresses and damping ratio to strain, to be adopted for the seismic local response analysis. According to the actual literature, many different models for the dynamic behaviour of the soil are provided; in the present work, the Yokota et al. [11] hyperbolic decay model was used to describe the pattern of shear modulus $G_{v}$; for the definition of damping $D$, the corresponding exponential variation law was then used. 


\subsection{Site response analysis}

The site response analysis was carried out in a free-field situation (i.e. neglecting the presence of the building) and in one-dimensional conditions, assumptions justified by the horizontal alignment of all of the soil layers. For the definition of the seismic input, 7 spectrum-compatible accelerograms were selected using the software Rexel 3.4 beta and Scalcona-2.0. Accelerograms were extracted from different database, selecting a set of input data for Tuscany for different return periods $\left(T_{R}\right)$.

The dynamic analysis of the subsoil was executed using STRATA; the subsoil model consisted of a finite number of flat and parallel layers equivalent to an elastic material placed on a visco-elastic half-space representing the bedrock. Each layer was considered homogeneous and isotropic, with thickness $h$, density $\rho$, stiffness modulus $G$ and transverse damping factor $D$. Once defined the seismic input to the bedrock, the response spectrum for the selected site was determined. To do this, the 7 accelerograms were scaled with reference to the design acceleration of the site $\left(a_{g}\right)$, defined according to D.M. 14/01/2008 in relation to the reference life of the building $\left(V_{R}\right)$ and the ultimate limit state. A nominal life $\left(V_{N}\right)$ equal to 50 years old, a class of use III $\left(C_{U}\right)$ and Life Safety limit state (SLV) were selected, resulting in a $V_{R}$ equal 75 years and a return period $T_{R}$ equal to 712 years. Table 1 shows all the data needed for the definition of the model. For each layer, the profiles of the normalized shear modulus $G$ and the damping ratio $D$, as a function of the level of deformation, were determined. Below the layer B4 a sandy layer was introduced up to a depth of 50 meters from the ground level, beyond which the presence of the bedrock was assumed. The dynamic characterization of the sand layer was carried out using available data from the literature about the subsoil of the Piazza dei Miracoli. The analysis of the local seismic response was then performed by calculating the average effects of the seven selected accelerograms. Figure $3 \mathrm{~b}$ shows the elastic response spectrum for $T_{R}=712$ years coming from the local seismic response analysis using the input signal obtained from the software SCALCONA, since it is calibrated on the Tuscan region and seismogenic areas.
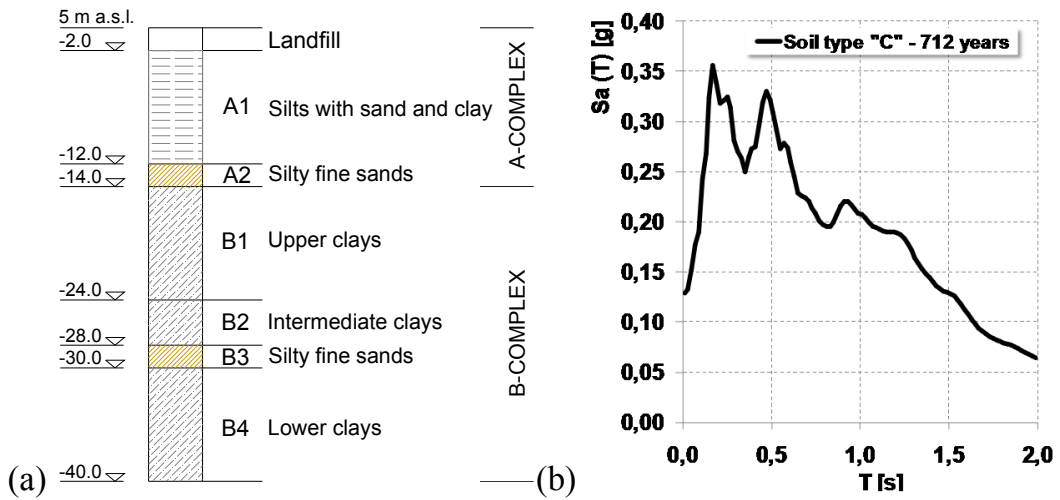

Figure 3: (a) Soil stratigraphy; (b) site response spectrum. 
Table 1: Significant parameters for seismic response analysis.

\begin{tabular}{lllll}
\hline Layer & Thickness $[\mathrm{m}]$ & $\curlyvee\left[\mathrm{kN} / \mathrm{m}^{3}\right]$ & $\mathrm{V}_{\mathrm{s}}[\mathrm{m} / \mathrm{s}]$ & Notes \\
\hline A1 & 12 & 19.35 & 200 & Silts with sand and clay \\
\hline A2 & 2 & 18.07 & 200 & Silty fine sand \\
\hline B1 & 10 & 17.08 & 180 & Upper clays \\
\hline B2 & 4 & 19.88 & 320 & Intermediate clays \\
\hline B3 & 2 & 19.11 & 360 & Silty fine sand \\
\hline B4 & 10 & 17.66 & 280 & Lower clays \\
\hline
\end{tabular}

\subsection{Foundation structures: investigations and survey}

Specific investigations were executed in to obtain data for the assessment of the structural safety of Palazzo La Sapienza (Figure 2). Several core drillings at different orientations [12] were executed to recover representative samples through the soil and the foundation structure to recover. The feedrate, the presence of the recirculating cooling water, the colour of the cooling water and eventual anomalies were measured. The bored material generally evidenced a relatively low strength recovery rates were very small.

The first investigations (P01, P02 and P03, Figure 2) were related to the columns of the "loggia". The borehole P01 aimed at investigating on the possible presence of a connection between the foundations of the different columns, while with boreholes P02and P03the homogeneity of the foundation system was analysed. The absence of any structural connection between foundations resulted clearly from the site investigation, with each column and pillar resting on a single footing. The foundation plane of the columns, with a squared footprint of $1.10 \mathrm{~m}$, was placed at about $-1.9 \mathrm{~m}$ from the ground level. The masonry of the recovery was irregular, with both solid bricks and stones connected with poor quality mortar. Boreholes P04 and P05 investigated the foundation of one of the pillars of the "loggia" at the entrance of the building. The masonry of the foundation was made up mainly of solid bricks with poor quality mortar, with a rather low presence of empty spaces in the surface; stone materials with very low strength were revealed. An isolated foundation placed at a depth of $-1.75 \mathrm{~m}$, with a rectangular footprint of $1.00 \times 1.80 \mathrm{~m}$ (long side in the direction of the alignment of the pillars) was assumed.

In the north part of the courtyard (borehole P06), a reduced presence of solid bricks and the large quantity of stone material was observed. The foundation was assumed to be continuous, placed at $-1.0 \mathrm{~m}$ and having a width equal to about $1.50 \mathrm{~m}$. At the borehole P07 resulted the presence of solid bricks with materials difficult to drill up to the maximum exploration depth; the foundation plan, characterized by a rectangular shape of width equal to about $2.40 \mathrm{~m}$, was placed at $-1.50 \mathrm{~m}$. Borehole P08 (located in the more recent part of the building) was limited to a lower depth; the foundation system was found at $-1.50 \mathrm{~m}$ and the width of about $0.90 \mathrm{~m}$ could be inferred. This low width value, together with 
the presence of wood in the coring, allowed the hypothesis (not confirmed) of the presence of wooden poles used in the past to improve the foundation.

Borehole P09 evidenced the absence of solid bricks and the presence of stones, together with areas of low strength. The foundation plan was located at $-0.60 \mathrm{~m}$, with a width equal to about $1.50 \mathrm{~m}$. Boreholes P10 and P11 (located along the external wall), evidenced a discrete consistency of the masonry and the lack of voids in the coring. The foundation of P10 was located at $-2.75 \mathrm{~m}$, for a width equal to $1.75 \mathrm{~m}$; a width of about $1.60 \mathrm{~m}$ and a depth equal to $-2.10 \mathrm{~m}$ were revealed through the borehole P11.

\section{Structural modelling and analysis}

\subsection{Modelling of the superstructure}

A numerical three-dimensional model of the structure was built up to perform the numerical analyses needed for the safety and performance check of the building as prescribed by D.M.14/01/2008 [1]. Such a complex building shall be considered more similar to a "structural aggregate" than to a single building, made up of different parts connected together during the centuries; the difficulty to model material discontinuities, disconnections between perpendicular walls, and other factors allowed the definition of a global numerical model that is representative of an "improved condition" of the structural system. The linear three-dimensional FEM model of the building (Figure 4) was built by using the code SAP 2000, with two-dimensional elements for the walls and onedimensional elements for the steel element of the floor slabs, the roofing and the library mezzanines. The vaulted surfaces were modelled with equivalent two-dimensional plane structural element. The mechanical characteristics of the masonry material were selected according to the results of in situ flat-jack tests and to the indications contained in the Ministerial Memorandum Circ. 617/2009, for the different types of masonry pattern. The presence of cracking phenomena was conventionally taken into consideration through the reduction of the stiffness of the masonry walls [1]. Loads were determined in relation to D.M. 14.01.2008; the effective weight of the books of the libraries was also estimated with good accuracy.

(a)

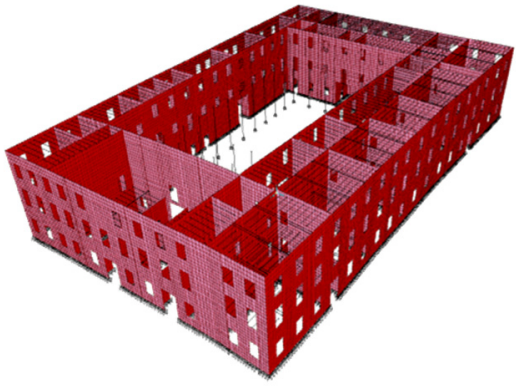

(b)

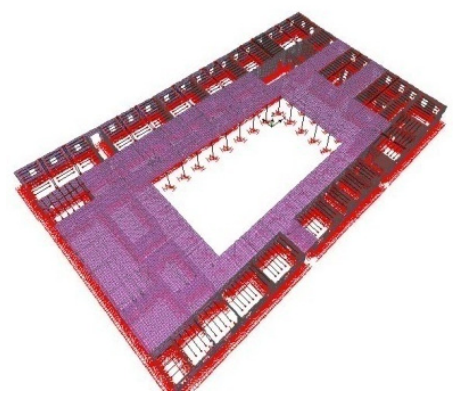

Figure 4: (a) Global model; (b) vaulted surfaces and frame elements of the storeys. 


\subsection{Modelling of the soil-structure interaction (SSI)}

The experimental investigations evidenced a significant geometric variability (both of depths and widths) of foundations, with the subsequent in-homogeneity of the mechanical response of the structural system, essentially for the strongly varying stiffness of the soil-foundation complex and of bearing capacities.

The interaction between the superstructure and the ground soil was represented through a nonlinear Winkler model, with elastic three-directional springs calibrated according to the results of the geotechnical investigations. The initial stiffness of the springs was determined adopting settlement formulations given by the theory of the elastic-half space [13]; the elastic properties of the soil were derived from the results of down-hole tests. Due to the different geometry, both in terms of depth and dimensions, different values of the initial stiffness $\left(K_{i n i}\right)$ were obtained for the different portions of the building. The horizontal stiffness (both in $\mathrm{x}$ and $\mathrm{y}$ directions) was assumed equal to the $25 \%$ of the vertical one. The stiffness of the Winkler springs was evaluated considering the effective dimension of the foundation structures and a spacing equal to $0.50 \mathrm{~m}$. Five different areas were recognized as necessary for a sound SSI modelling of the soil foundation system (Figure 5); the corresponding values of effective vertical stiffness $\left(k_{v}\right)$ are presented in Table 2 , being $B$ the average width of the

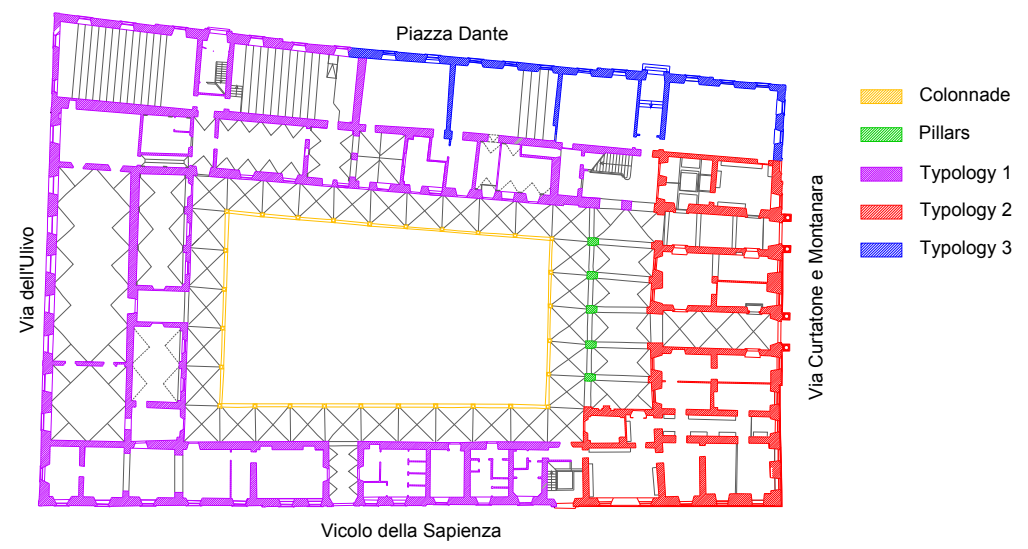

Figure 5: Schematization of foundations according to the values of stiffness.

Table 2: Elastic stiffness values for vertical springs adopted in the model.

\begin{tabular}{llcccl}
\hline Foundation typology & $\mathrm{K}_{\text {ini }}[\mathrm{kPa} / \mathrm{m}]$ & $\mathrm{i}[\mathrm{m}]$ & $\mathrm{B}[\mathrm{m}]$ & $\mathrm{A}\left[\mathrm{m}^{2}\right]$ & $\mathrm{k}_{\mathrm{v}}[\mathrm{N} / \mathrm{mm}]$ \\
\hline Colonnade & 32560 & - & - & 1.21 & 39398 \\
\hline Pillars & 25300 & - & - & 1.80 & 45540 \\
\hline Typology 1 & 4500 & 0.5 & 1.6 & - & 3600 \\
\hline Typology 2 & 3200 & 0.5 & 2.4 & - & 3840 \\
\hline Typology 3 & 7600 & 0.5 & 0.9 & - & 3420 \\
\hline
\end{tabular}


foundation, $i$ the springs' spacing in the model and $A$ the foundation area for columns and pillars.

\subsection{Numerical analyses and safety assessment of the superstructure}

Linear dynamic analysis was performed; the response spectrum resulting from the local seismic analysis was adopted, with a behaviour factor $q$ equal to 2.25.

Safety checks (i.e. shear, bending and compression in and out of plane) were executed; careful evaluations regarding the potential activation of local collapse mechanisms (i.e. tilting of façades, rotation and tilting of corners, effects linked to thrust on vaults, arches, etc.) were also performed.

The global checks on masonry walls evidenced that the building essentially satisfies the safety requirements with regard to both static and seismic actions, with the exception of extremely small-sized, slender elements characterized by a considerable heterogeneity in shape and materials and by extensive cracking due to the progressive structural layering and modifications made to the building.

Relatively critical conditions were encountered in the area of the historical Aula Magna, where two of the original spaces of the colonnade were closed-up, and in the proximity of the double volume of the new Aula Magna. Problems of out-of-plane overturning were found in correspondence to the interior wall of the $1^{\text {st }}$ floor towards the arcade parallel to Piazza Dante, where the perpendicular masonry restraints were removed without taking account their structural effects, as well as in correspondence to the wall of the double volume of the new Aula Magna. Floors and vaults, with the exception of an under-dimensioned slab on the building's $2^{\text {nd }}$ floor, did not evidence significant structural deficiencies in terms of either strength or deformability. The wooden roofing structures presented a widespread degradation and consequently often did not satisfy the safety requirements.

Apart from these structural issues, many other intrinsic critical situations were identified as a consequence of the building's morphological conformation itself. Such problems were frequently aggravated by the modifications executed over the centuries in relation to the architectural and functional needs.

\section{Evaluation of differential foundation displacements}

For what concerns the safety assessment of foundations, the ultimate load of the foundation soil, to be compared with the resulting pressures coming from numerical analyses on the global model of the building, was determined through a classical approach, applying to the various sections the Brinch Hansen [14] equation. Table 3 shows the values of the mean ultimate loads, evaluated with reference to a homogeneous soil with a shear strength angle equal to $36^{\circ}$ and a saturated weight equal to $19.35 \mathrm{kN} / \mathrm{m}^{3}$, for the different areas of Figure 5 .

The results obtained for the foundation - soil system, in terms of unit load towards subsidence are presented in Figure 6 for all the considered sections; as visible, different foundation elements presented a very different behaviour in relation to geometry. The most significant differences were related to the secant 
stiffness in the initial part of the diagram (up to $1.0 \mathrm{MPa}$ ). The structural analysis allowed the estimation of the unit loads on foundations, through the assignment of the different stiffness values to different portions of the building. The analysis was executed modelling the various loading conditions considering both the ultimate and the damage limit states, including or neglecting the live load. Table 3 shows the unit loads for the different portions of the building and for the loading combination including only dead loads (minimum value) and including also the live loads (maximum value). The non-homogeneity of loads, together with the variability of stiffness, very likely caused the differential settlement of the different portions of the building and the possible damages related to the increase of loads during the centuries.

Table 3: Mean limit loads (Brinch Hansen) and contact stresses on the soil.

\begin{tabular}{llccl}
\hline Portion & $q_{\lim }[\mathrm{kPa}]$ & Min. stress $[\mathrm{kPa}]$ & Max. stress $[\mathrm{kPa}]$ & Notes \\
\hline Colonnade & 2700 & 176 & 340 & \\
\hline Pillars & 2250 & 133 & 469 & \\
\hline Typology 1 & $1270-3000$ & 86 & 139 & P6 - P10 - P11 \\
\hline Typology 2 & 1900 & 49 & 95 & P7 - P9 \\
\hline Typology 3 & 1650 & 140 & 211 & P8 \\
\hline
\end{tabular}

(a)
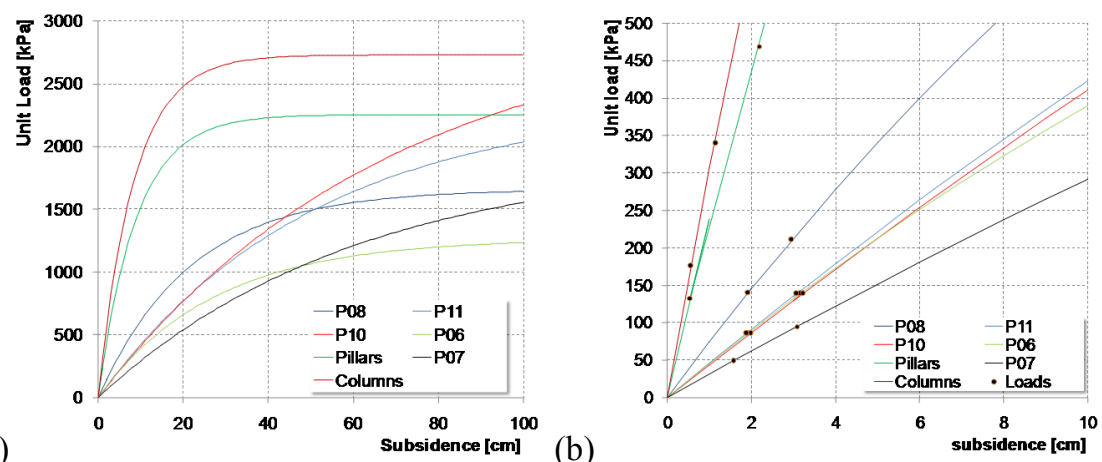

Figure 6: (a) Unit load-settlement curves for the different investigated sections, (b) estimates for different building zones.

Figure 6 shows the summary of the information regarding acting loads and mechanical performance of the foundation-soil system. A significant difference was revealed between the external and the internal portions of the building (the last one represented by the colonnade and pillars of the internal courtyard). The above mentioned differences may lead to significant damages in the areas characterized by a higher gap between foundation stiffness or by a strong variability of acting loads. 


\section{Conclusions}

As a consequence of what was presented in this paper, the analysis of the SSF (soil-structure-foundation) interaction represents a very significant topic in the static analysis and vulnerability assessment of the cultural heritage.

A detailed knowledge of the geotechnical parameters of the soil and of the effective geometry of the foundation system allows the achievement of more reliable information about the state of art of the building and to quantify the fulfillment of the safety requirements imposed by actual standards.

A wide in situ experimental investigation as the one carried out for Palazzo La Sapienza in Pisa, allowed the definition of the effective stratigraphy of the subsoil and the assessment of the expected mechanical response of the foundation system: the differences revealed in the various portions of the building, in terms of bearing capacity and stiffness of the foundations, were then directly connected to the different subsidence observed nowadays, evidenced by the framework of the visible damage as consequence of the increasing loads acting on the superstructure. The correct definition of the seismic input, executed through a local seismic response analysis, moreover allows the determination of a realistic seismic demand on the building, with reliable results, avoiding extreme overestimation of actions.

\section{References}

[1] D. M. Infrastrutture Trasporti 14 gennaio 2008, Norme Tecniche per le Costruzioni, 2008 (in Italian).

[2] Linee Guida per la valutazione e riduzione del rischio sismico del patrimonio culturale allineate alle nuove Norme Tecniche per le Costruzioni (D.M. 14/01/2008), 2010.

[3] FEMA 547. Techniques for the Seismic Rehabilitation of Existing Buildings. Federal Emergency Management Agency, Washington DC, 2006.

[4] Masia M.J., Kleeman P.W., Melchers R.E. Modeling Soil-Structure Interaction for Masonry Structures. Journal of Structural Engineering, 130(4), 641-649, 2004.

[5] Gallipoli M.R. et al. The role of site effects in the comparison between code provisions and the near field strong motion of the Emilia 2012 earthquakes. Bulletin of Earthquake Engineering, 12, 2211-2230, 2014.

[6] Pitilakis D., Karatzetzou A. Dynamic stiffness of monumental flexible masonry foundations. Bulletin of Earthquake Engineering, 13, 67-82, 2015.

[7] Gazetas G. Formulas and charts for impedances of surface and embedded foundations. Journal of Geotechnical Engineering, 117(9): 1363-1381, 1991.

[8] Chopra A.K. Dynamics of structures: theory and applications to earthquake engineering, $4^{\text {th }}$ edn. Prentice Hall, Englewood Cliffs, 2011. 
[9] Ceroni F., Sica S., Pecce M., Garofano A.. Effect of Soil-Structure Interaction on the dynamic behaviour of masonry and RC buildings. $15^{\text {th }}$ WCEE, September 24-28, 2012, Lisbon, Portugal.

[10] Mylonakis G, Gazetas G. Seismic soil-structure interaction: beneficial or detrimental? Journal of Earthquake Engineering, 4(3), 377-401, 2000.

[11] Yokota K., Imai T., Konno M. (1981) - Dynamic deformation characteristics of soils determined by laboratory tests. OYO Tec. Rep. 3, 13-37, 1981.

[12] Squeglia N. The Rebuilding of San Piero a Grado bell Tower, Proc. Geotechnical Engineering for the Preservation of Monuments and Historic Sites, Bilotta et Al Eds., CRC Press. 709-716, 2013.

[13] Groth N.N., Chapman C.R. Computer evaluation of deformations due to subsurface loads in a semi-infinite elastic medium. B.E. Thesis, University of Sydney, Australia, 1969.

[14] Brinch Hansen J. A general Formula for Bearing Capacity, Danish Geotechnical Institute, Bull. 11, 1961. 